\title{
A comparison of CKD-EPI estimated glomerular filtration rate and measured creatinine clearance in recently admitted critically ill patients with normal plasma creatinine concentrations
}

Andrew A Udy ${ }^{1,2^{*}}$, Fraser JA Morton ${ }^{2}$, Sallyanne Nguyen-Pham ${ }^{1}$, Paul Jarrett ${ }^{2}$, Melissa Lassig-Smith ${ }^{2}$, Janine Stuart ${ }^{2}$, Rachel Dunlop ${ }^{2}$, Therese Starr ${ }^{2}$, Robert J Boots ${ }^{1,2}$ and Jeffrey Lipman ${ }^{1,2}$

\begin{abstract}
Background: The Chronic Kidney Disease Epidemiology Collaboration (CKD-EPI) estimated glomerular filtration rate (eGFR) has been widely integrated into clinical practice. Although useful in screening for CKD, its' application in critically ill patients with normal plasma creatinine concentrations remains uncertain. The aim of this study was to assess the performance of CKD-EPI eGFR in comparison to creatinine clearance $\left(\mathrm{CL}_{C R}\right)$ in this setting.

Methods: This prospective observational study was performed in a tertiary level, university affiliated intensive care unit (ICU). Study participants had to have an expected ICU length of stay $>24$ hours, a plasma creatinine concentration $<121 \mu \mathrm{mol} / \mathrm{L}$, and no history of prior renal replacement therapy or CKD. CKD-EPI eGFR was compared against 8-hour measured urinary $\mathrm{CL}_{\mathrm{CR}}$. Data capture occurred within 48 hours of admission.

Results: One hundred and ten patients $(n=110)$ were enrolled in the study. $63.6 \%$ were male, the mean age was 50.9 (16.9) years, 57.3\% received invasive mechanical ventilation, and $30 \%$ required vasopressor support. The mean $\mathrm{CL}_{\mathrm{CR}}$ was $125(45.1) \mathrm{ml} / \mathrm{min} / 1.73 \mathrm{~m}^{2}$, compared to a CKD-EPI eGFR of $101(23.7) \mathrm{ml} / \mathrm{min} / 1.73 \mathrm{~m}^{2}(P<0.001)$. Moderate correlation was evident $(r=0.72)$, although there was significant bias and imprecision $\left(24.4+/-32.5 \mathrm{ml} / \mathrm{min} / 1.73 \mathrm{~m}^{2}\right)$. In those patients with a CKD-EPI eGFR between 60-119 $\mathrm{ml} / \mathrm{min} / 1.73 \mathrm{~m}^{2}(\mathrm{n}=77), 41.6 \%$ displayed augmented renal clearance $\left(\mathrm{CL}_{\mathrm{CR}} \geq 130 \mathrm{ml} / \mathrm{min} / 1.73 \mathrm{~m}^{2}\right)$, while $7.8 \%$ had a $\mathrm{CL}_{\mathrm{CR}}<60 \mathrm{ml} / \mathrm{min} / 1.73 \mathrm{~m}^{2}$.

Conclusions: These data suggest CKD-EPI eGFR and measured $\mathrm{CL}_{C_{R}}$ produce significantly disparate results when estimating renal function in this population. Clinicians should consider carefully which value they employ in clinical practice, particularly drug dose modification.
\end{abstract}

\section{Background}

Accurate assessment of renal function is a priority in the management of critically ill patients. Clinicians regularly utilize such information to help guide drug dosing, optimize fluid, acid-base, and electrolyte management, tailor nutritional requirements, and assess the need for renal replacement therapy (RRT). Rising plasma creatinine

\footnotetext{
* Correspondence: andrew_udy@health.qld.gov.au

'Burns, Trauma, and Critical Care Research Centre, The University of Queensland, Royal Brisbane and Womens Hospital, Butterfield Street, Herston 4029, Queensland, Australia

2Department of Intensive Care Medicine, Royal Brisbane and Womens Hospital, Level 3 Ned Hanlon Building, Butterfield Street, Herston 4029, Queensland,
} Australia

\section{Biomed Central}

(c) 2013 Udy et al.; licensee BioMed Central Ltd. This is an open access article distributed under the terms of the Creative Commons Attribution License (http://creativecommons.org/licenses/by/2.0), which permits unrestricted use, distribution, and reproduction in any medium, provided the original work is properly cited.
(CR) concentrations often trigger clinical interventions, including dose reduction of renally eliminated agents. In contrast, plasma CR concentrations within the reported reference range appear to be less useful. Normal values in the critically ill have been associated with both augmented creatinine clearance $\left(\mathrm{CL}_{\mathrm{CR}}\right)$ [1], and occult acute kidney injury (AKI) [2].

Driven primarily by a desire to more effectively monitor and screen for chronic kidney disease (CKD), formulae using simple demographic variables have been developed to estimate the glomerular filtration rate (eGFR). The most commonly applied include the Modification of Diet in Renal Disease (MDRD) [3], and newer CKD Epidemiology 
Collaboration (CKD-EPI) [4] equations. Their application is based principally on large cohort studies that effectively stratify patients in terms of long-term clinical risk $[5,6]$. This has led to recommendations for widespread laboratory reporting of eGFR $[7,8]$.

While these initiatives represent key developments in improving the quality of care for patients with CKD, some clinicians have expressed concern about the ubiquitous application of eGFR, particularly in dose modification [9]. Use of formulae to help guide drug dosing represents an attractive approach, although an ability to trigger both dose reduction and escalation is required. Currently there is a paucity of data examining whether eGFR could be used in place of conventional measures for such a purpose, particularly in the critical care environment. The aim of this study was therefore to compare CKD-EPI eGFR with measured urinary $\mathrm{CL}_{\mathrm{CR}}$, in a cohort of recently admitted critically ill patients with normal plasma creatinine concentrations.

\section{Methods \\ Setting}

This study was performed in a tertiary level, university affiliated, metropolitan intensive care unit (ICU), over a two-month period. Enrolment utilized convenience sampling. Ethical approval was obtained from the institutional Human Research Ethics Committee (HREC/09/ QRBW/192), with written informed consent obtained from either the patient or their nominated substitute decision-maker.

\section{Study population}

Study participants had to have an anticipated ICU length of stay $(\mathrm{LOS})>24$ hours, a plasma CR concentration < $121 \mu \mathrm{mol} / \mathrm{L}$, and no history of prior renal replacement therapy or CKD. Patients were excluded if: a) either invasive haemodynamic monitoring or an indwelling urinary catheter (IDC) were not employed as part of standard management; b) they were $<18$ years of age; c) they were pregnant; d) rhabomyolysis was clinically suspected or the admission plasma creatinine kinase was $>5000 \mathrm{IU} / \mathrm{L}$; or e) they were in the 'risk' category or greater for AKI, as defined by the RIFLE criteria [10]. Patients undergoing an operative procedure within 24 hours prior to admission were classified as 'surgical'. Planned post-operative admissions were considered 'elective'.

\section{Interventions}

Demographic and illness severity characteristics, including; age, gender, anthropometric measures, diagnosis, and acute physiology and chronic health evaluation (APACHE) II scores were recorded on admission. Modified (excluding the neurological component) sequential organ failure assessment (SOFA) scores, ventilation parameters, 24-hour fluid balance, vasopressor administration, and diuretic use, were recorded prospectively at the time of $\mathrm{CL}_{\mathrm{CR}}$ assessment. ICU and hospital LOS, and ICU mortality were determined for all patients. Data capture occurred within 48 hours of admission to the ICU, as determined by staff availability and admission time.

An 8-hour measured $\mathrm{CL}_{\mathrm{CR}}$ was obtained using the following method. Urine was collected via the IDC between midnight and $0800 \mathrm{hrs}$, following which urinary volume and CR concentration were determined by laboratory analysis. Concurrent plasma CR concentrations were obtained at a point mid-way through the urinary collection, following which $\mathrm{CL}_{\mathrm{CR}}$ was calculated using the formula listed below. CR measurement in plasma and urine utilised automated analysers employing a modified Jaffe (alkaline picrate) technique, representing an isotope dilution mass spectrometry (IDMS) traceable assay.

As per convention, $\mathrm{CL}_{\mathrm{CR}}$ values were normalised to a body surface area (BSA) of $1.73 \mathrm{~m}^{2}$. The abbreviated 175 MDRD (175 eGFR), CKD-EPI (CKD-EPI eGFR), and Cockcroft-Gault ( $\mathrm{CG} \mathrm{CL}_{\mathrm{CR}}$ ) equations were used to calculate estimates for comparison, as outlined below. Augmented renal clearance (ARC) was defined as a measured 8-hr $\mathrm{CL}_{\mathrm{CR}} \geq 130 \mathrm{ml} / \mathrm{min} / 1.73 \mathrm{~m}^{2}$, given the association with sub-therapeutic drug concentrations, when using standard doses of renally eliminated antibiotics $[11,12]$.

\section{List of equations employed}

$$
\begin{aligned}
\mathrm{BSA}=0.007184 \times(\mathrm{Ht})^{0.725} \times(\mathrm{Wt})^{0.425} \\
\mathrm{CL}_{\mathrm{CR}}=\left(\mathrm{U}_{\mathrm{CR}} \times \mathrm{U}_{\mathrm{Vol}} / \mathrm{P}_{\mathrm{CR}} \times 480\right) \times 1.73 / \mathrm{BSA} \\
\mathrm{CGCL}_{\mathrm{CR}}=[(140-\text { age }) \times \mathrm{Wt} \times(1.23 \text { if male, } 1.04 \text { if female })] \\
/ \mathrm{P}_{\mathrm{CR}} \times 1.73 / \mathrm{BSA} \\
175 \mathrm{eGFR}=175 \times\left(\mathrm{P}_{\mathrm{CR}} \times 0.0113\right)^{-1.154} \times \text { age }^{-0.203} \\
(\times 0.742 \text { if female })
\end{aligned}
$$

\section{CKD-EPI eGFR}

$$
\begin{aligned}
& \text { Females, } \mathrm{P}_{\mathrm{CR}} \leq 62= 144 \times\left(\mathrm{P}_{\mathrm{CR}} \times 0.0113 / 0.7\right)^{-0.329} \\
& \times 0.993^{\text {age }} \\
& \text { Females, } \mathrm{P}_{\mathrm{CR}}>62= 144 \times\left(\mathrm{P}_{\mathrm{CR}} \times 0.0113 / 0.7\right)^{-1.209} \\
& \times 0.993^{\text {age }} \\
& \text { Males, } \mathrm{P}_{\mathrm{CR}} \leq 80=141 \times\left(\mathrm{P}_{\mathrm{CR}} \times 0.0113 / 0.9\right)^{-0.411} \times 0.993^{\text {age }} \\
& \text { Males, } \mathrm{P}_{\mathrm{CR}}>80= 141 \times\left(\mathrm{P}_{\mathrm{CR}} \times 0.0113 / 0.9\right)^{-1.209} \\
& \times 0.993^{\text {age }}
\end{aligned}
$$

Where $\quad \mathrm{CL}_{\mathrm{CR}}=8-\mathrm{hr}$ Creatinine Clearance $(\mathrm{ml} / \mathrm{min} /$ $\left.1.73 \mathrm{~m}^{2}\right), \mathrm{U}_{\mathrm{CR}}=$ Urinary Creatinine Concentration $(\mu \mathrm{mol} / \mathrm{L})$, $\mathrm{U}_{\mathrm{Vol}}=$ Urinary volume $(\mathrm{ml}), \mathrm{P}_{\mathrm{CR}}=$ Plasma Creatinine Concentration $(\mu \mathrm{mol} / \mathrm{L}), \mathrm{BSA}=$ Body Surface Area $\left(\mathrm{m}^{2}\right), \mathrm{Ht}=$ Height $(\mathrm{cm}), \mathrm{Wt}=$ Weight $(\mathrm{kg}), \mathrm{CG} \mathrm{CL}_{\mathrm{CR}}=$ Cockcroft-Gault 
Creatinine Clearance $\left(\mathrm{ml} / \mathrm{min} / 1.73 \mathrm{~m}^{2}\right), 175$ eGFR $=$ Abbreviated Modification of Diet in Renal Disease 175 formula $\left(\mathrm{ml} / \mathrm{min} / 1.73 \mathrm{~m}^{2}\right)$, and, CKD-EPI eGFR = Chronic Kidney Disease Epidemiology Collaboration Equation $(\mathrm{ml} / \mathrm{min} /$ $1.73 \mathrm{~m}^{2}$ ), age (in years).

\section{Statistical analysis}

Continuous data are presented as the mean (SD) or median [IQR] depending on adherence to a normal distribution. Normality was assessed by visual inspection, and a one-sample Kolmogorov-Smirnov test. Categorical data are presented as counts (\%). Correlations were assessed using a Pearson correlation coefficient (r). Precision and bias were examined using a Bland-Altman plot, with the bias representing the mean difference between each variable, and precision being one SD from the mean. Comparison of continuous data utilized a paired Students $T$-test. A twosided $P$-value $<0.05$ was considered as statistical significance, and all analyses were performed using SPSS version 21 (IBM Corporation, Armonk, New York) and PRISM version 5 (GraphPad Software Inc, La Jolla, California).

\section{Results}

One hundred and ten patients $(\mathrm{n}=110)$ were enrolled in the study, with all participants completing an $8-\mathrm{hr} \mathrm{CL}_{\mathrm{CR}}$. Demographic, admission, illness severity and outcome data are presented in Table 1 . As illustrated, approximately two-thirds of the cohort was male, the patients were relatively young (50.9 (16.9) years), greater than $50 \%$ received invasive mechanical ventilation, and about one-third required vasopressor support. Less than $15 \%$ were elective cases, with the majority manifesting systemic inflammation, with or without undergoing prior surgery. As per protocol, plasma $\mathrm{CR}$ concentrations were within the normal reference range $(68.5(21.8) \mu \mathrm{mol} / \mathrm{L})$, and did not change significantly in the following $24 \mathrm{hrs}(P=0.157)$, where data were available. The mean $8-\mathrm{hr} \mathrm{CL}_{\mathrm{CR}}$ was 125 (45.1) $\mathrm{ml} / \mathrm{min} / 1.73 \mathrm{~m}^{2}, 48.2 \%(\mathrm{n}=53)$ manifested ARC, and 10 (9.1\%) had a $\mathrm{CL}_{\mathrm{CR}}<60 \mathrm{ml} / \mathrm{min} / 1.73 \mathrm{~m}^{2}$.

A comparison of measured 8-hr $\mathrm{CL}_{\mathrm{CR}}$ and 175 eGFR, CG $\mathrm{CL}_{\mathrm{CR}}$, and CKD-EPI eGFR in all patients, and each diagnostic category separately, are presented in Table 2. Scatter graphs using all data points are provided in Figure 1. Equivalent Bland-Altman plots are presented in Figure 2. Across all groups, the observed bias is greatest with the CKD-EPI equation. A significant proportional error is also apparent, with higher average values significantly correlated with a larger positive bias (Figure $2 \mathrm{C}, \mathrm{r}=0.705, P<0.001$ ). This was not evident with either the 175 eGFR $(\mathrm{r}=0.102$, $P=0.289)$, or $\mathrm{CG} \mathrm{CL}_{\mathrm{CR}}(\mathrm{r}=0.103, P=0.285)$ formulae.

8-hr $\mathrm{CL}_{\mathrm{CR}}$ values were used to categorize patients into four groups; < 90, 90-119, 120-149, and $\geq 150 \mathrm{ml} / \mathrm{min} /$ $1.73 \mathrm{~m}^{2}$. Comparisons with each mathematical estimate are presented in Table 3 and Figure 3. As illustrated, CKD-
Table 1 Demographic, illness severity and treatment data

\begin{tabular}{|c|c|}
\hline Variable & $N=110$ \\
\hline Age, years, mean (SD) & $50.9(16.9)$ \\
\hline Gender, male/female, n (\%) & $\begin{array}{l}70(63.6) / 40 \\
\quad(36.4)\end{array}$ \\
\hline Height, m, mean (SD) & $1.71(0.09)$ \\
\hline Weight, kg, mean (SD) & $80.9(22.4)$ \\
\hline Body surface area, $\mathrm{m}^{2}$, mean (SD) & $1.92(0.24)$ \\
\hline APACHE II, mean (SD) & $16.1(6.20)$ \\
\hline Modified SOFA, median [IQR] & $3[2-5]$ \\
\hline \multicolumn{2}{|l|}{ Admission type, n (\%) } \\
\hline - Elective & $15(13.6)$ \\
\hline - Emergency & $33(30.0)$ \\
\hline - Surgical emergency & $37(33.6)$ \\
\hline - Trauma & $25(22.7)$ \\
\hline Mechanical ventilation, $n(\%)(n=108)$ & $63(57.3)$ \\
\hline Intravenous contrast administration, $n(\%)(n=109)$ & $30(27.3)$ \\
\hline Frusemide administration, n (\%) & $13(11.8)$ \\
\hline Mannitol administration, n (\%) & $4(3.6)$ \\
\hline Vasopressors, n (\%) & $33(30.0)$ \\
\hline Systemic inflammatory response syndrome, n (\%) & $95(86.4)$ \\
\hline Plasma creatinine concentration, $\mu \mathrm{mol} / \mathrm{L}$, mean (SD) & $68.5(21.8)$ \\
\hline $\begin{array}{l}\text { Plasma creatinine concentration }+24 \mathrm{hrs}, \mu \mathrm{mol} / \mathrm{L} \text {, mean } \\
\text { (SD) }(n=80)\end{array}$ & $63.0(19.6)$ \\
\hline ICU length of stay, days, median [IQR] & $4[2-10]$ \\
\hline ICU mortality, n (\%) & $11(10)$ \\
\hline
\end{tabular}

APACHE-Acute physiology and chronic health evaluation, ICU-Intensive care unit, SOFA-sequential organ failure assessment.

EPI eGFR was generally higher than $\mathrm{CL}_{\mathrm{CR}}$ in the lower range $\left(<90 \mathrm{ml} / \mathrm{min} / 1.73 \mathrm{~m}^{2}\right)$, although the opposite was observed at higher values. Correlation was generally poor in each group (Table 3$)$. In those patients with a calculated CKD-EPI eGFR between $60-119 \mathrm{ml} / \mathrm{min} / 1.73 \mathrm{~m}^{2}(\mathrm{n}=77)$, 8-hr $\mathrm{CL}_{\mathrm{CR}}$ values were significantly higher (118 (38.3) vs 96 (16.6) $\left.\mathrm{ml} / \mathrm{min} / 1.73 \mathrm{~m}^{2}, P<0.001\right), 41.6 \%(\mathrm{n}=32)$ displayed ARC, and $7.8 \%(\mathrm{n}=6)$ had a $\mathrm{CL}_{\mathrm{CR}}<60 \mathrm{ml} / \mathrm{min} / 1.73 \mathrm{~m}^{2}$.

\section{Discussion}

To our knowledge, this is the first report of CKD-EPI eGFR performance in a cohort of Australian patients recently admitted to the ICU. These data demonstrate significant disparity between CKD-EPI eGFR and measured $\mathrm{CL}_{\mathrm{CR}}$ in patients with normal plasma CR concentrations. Despite an overall reasonable correlation, bias and precision were unacceptable across a range of values. This highlights that clinicians must carefully consider which estimate of renal function they use in clinical decision-making, as these may be very dissimilar. A modest fraction of study participants 
Table 2 Comparison, correlation, bias and precision between measured 8-hr $\mathrm{CL}_{\mathrm{CR}}$ and mathematical estimates in all patients, and each diagnostic sub-group

\begin{tabular}{|c|c|c|c|}
\hline & $\begin{array}{c}\text { Mean } \\
\text { (SD) }\end{array}$ & $r(P$-value $)$ & $\begin{array}{l}\text { Bias +/- } \\
\text { precision }\end{array}$ \\
\hline \multicolumn{4}{|l|}{ All patients $(n=110)$} \\
\hline $\mathrm{CL}_{\mathrm{CR},}, \mathrm{ml} / \mathrm{min} / 1.73 \mathrm{~m}^{2}$ & $125(45.1)$ & & \\
\hline $\begin{array}{l}175 \mathrm{eGFR}, \mathrm{ml} / \mathrm{min} / \\
1.73 \mathrm{~m}^{2}\end{array}$ & $110(41.6)^{*}$ & $\begin{array}{l}0.600 \\
(<0.001)\end{array}$ & $15.6+/-38.9$ \\
\hline $\begin{array}{l}\mathrm{CG} \mathrm{CL}_{\mathrm{CR},}, \mathrm{ml} / \mathrm{min} / \\
1.73 \mathrm{~m}^{2}\end{array}$ & $119(41.7)$ & $\begin{array}{c}0.638 \\
(<0.001)\end{array}$ & $6.23+/-37.1$ \\
\hline $\begin{array}{l}\text { CKD-EPI eGFR, } \\
\mathrm{ml} / \mathrm{min} / 1.73 \mathrm{~m}^{2}\end{array}$ & $101(23.7)^{*}$ & $\begin{array}{c}0.720 \\
(<0.001)\end{array}$ & $24.4+/-32.5$ \\
\hline \multicolumn{4}{|c|}{ Elective admissions $(n=15)$} \\
\hline $\mathrm{CL}_{\mathrm{CR}}, \mathrm{ml} / \mathrm{min} / 1.73 \mathrm{~m}^{2}$ & $118(27.2)$ & & \\
\hline $\begin{array}{l}175 \mathrm{eGFR}, \mathrm{ml} / \mathrm{min} / \\
1.73 \mathrm{~m}^{2}\end{array}$ & $115(51.2)$ & $0.325(0.237)$ & $2.77+/-49.5$ \\
\hline $\begin{array}{l}\mathrm{CG} \mathrm{CL}_{\mathrm{CR},} \mathrm{ml} / \mathrm{min} / \\
1.73 \mathrm{~m}^{2}\end{array}$ & $119(44.1)$ & $0.531(0.042)$ & $-1.04+/-37.5$ \\
\hline $\begin{array}{l}\text { CKD-EPI eGFR, } \\
\mathrm{ml} / \mathrm{min} / 1.73 \mathrm{~m}^{2}\end{array}$ & $101(20.0)$ & $0.488(0.065)$ & $17.2+/-24.7$ \\
\hline \multicolumn{4}{|c|}{ Emergency admission ( $\mathrm{n}=33)$} \\
\hline $\mathrm{CL}_{\mathrm{CR}}, \mathrm{ml} / \mathrm{min} / 1.73 \mathrm{~m}^{2}$ & $113(50.0)$ & & \\
\hline $\begin{array}{l}175 \mathrm{eGFR}, \mathrm{ml} / \mathrm{min} / \\
1.73 \mathrm{~m}^{2}\end{array}$ & $114(47.9)$ & $\begin{array}{c}0.624 \\
(<0.001)\end{array}$ & $-0.77+/-42.5$ \\
\hline $\begin{array}{l}\mathrm{CG} \mathrm{CL}_{\mathrm{CR},}, \mathrm{ml} / \mathrm{min} / \\
1.73 \mathrm{~m}^{2}\end{array}$ & $123(49.1)$ & $\begin{array}{c}0.599 \\
(<0.001)\end{array}$ & $-10.4+/-44.3$ \\
\hline $\begin{array}{l}\text { CKD-EPI eGFR, } \\
\mathrm{ml} / \mathrm{min} / 1.73 \mathrm{~m}^{2}\end{array}$ & $99(27.6)^{* *}$ & $\begin{array}{c}0.692 \\
(<0.001)\end{array}$ & $13.8+/-36.8$ \\
\hline \multicolumn{4}{|c|}{ Surgical emergency admission $(n=37)$} \\
\hline $\mathrm{CL}_{\mathrm{CR},}, \mathrm{ml} / \mathrm{min} / 1.73 \mathrm{~m}^{2}$ & $125(46.4)$ & & \\
\hline $\begin{array}{l}175 \mathrm{eGFR}, \mathrm{ml} / \mathrm{min} / \\
1.73 \mathrm{~m}^{2}\end{array}$ & $101(37.2)^{*}$ & $\begin{array}{c}0.741 \\
(<0.001)\end{array}$ & $23.7+/-31.3$ \\
\hline $\begin{array}{l}\mathrm{CG} \mathrm{CL}_{\mathrm{CR},} \mathrm{ml} / \mathrm{min} / \\
1.73 \mathrm{~m}^{2}\end{array}$ & $108(37.5)$ & $\begin{array}{c}0.753 \\
(<0.001)\end{array}$ & $16.4+/-30.6$ \\
\hline $\begin{array}{l}\text { CKD-EPI eGFR, } \\
\mathrm{ml} / \mathrm{min} / 1.73 \mathrm{~m}^{2}\end{array}$ & $95(23.7)^{*}$ & $\begin{array}{c}0.779 \\
(<0.001)\end{array}$ & $29.5+/-31.6$ \\
\hline \multicolumn{4}{|c|}{ Trauma admission $(n=25)$} \\
\hline $\mathrm{CL}_{\mathrm{CR},}, \mathrm{ml} / \mathrm{min} / 1.73 \mathrm{~m}^{2}$ & $146(39.5)$ & & \\
\hline $\begin{array}{l}175 \mathrm{eGFR}, \mathrm{ml} / \mathrm{min} / \\
1.73 \mathrm{~m}^{2}\end{array}$ & $114(32.0)^{*}$ & $\begin{array}{c}0.745 \\
(<0.001)\end{array}$ & $32.7+/-26.5$ \\
\hline $\begin{array}{l}\mathrm{CG} \mathrm{CL}_{\mathrm{CR},} \mathrm{ml} / \mathrm{min} / \\
1.73 \mathrm{~m}^{2}\end{array}$ & $\begin{array}{c}129(33.8) \\
* *\end{array}$ & $\begin{array}{c}0.757 \\
(<0.001)\end{array}$ & $17.4+/-26.1$ \\
\hline $\begin{array}{l}\text { CKD-EPI eGFR, } \\
\mathrm{ml} / \mathrm{min} / 1.73 \mathrm{~m}^{2}\end{array}$ & $111(17.4)^{*}$ & $\begin{array}{c}0.772 \\
(<0.001)\end{array}$ & $35.2+/-28.4$ \\
\hline
\end{tabular}

${ }^{*} P<0.001$, when compared to $\mathrm{CL}_{\mathrm{CR}} *{ }^{*} P<0.05$, when compared to $\mathrm{CL}_{\mathrm{CR}}$ $\mathrm{CL}_{\mathrm{CR}}=8$-hr Creatinine Clearance, $\mathrm{CG} \mathrm{CL}_{\mathrm{CR}}=$ Cockcroft-Gault Creatinine Clearance, 175 eGFR = Abbreviated Modification of Diet in Renal Disease 175 formula, CKD-EPI eGFR = Chronic Kidney Disease Epidemiology Collaboration Equation, $r=$ Pearson correlation coefficient.

displayed $\mathrm{CL}_{\mathrm{CR}}$ measures significantly higher than might be expected, a finding that requires further evaluation.

Albeit the CKD-EPI equation is relatively new in Australian practice, ours is not the only study to explore

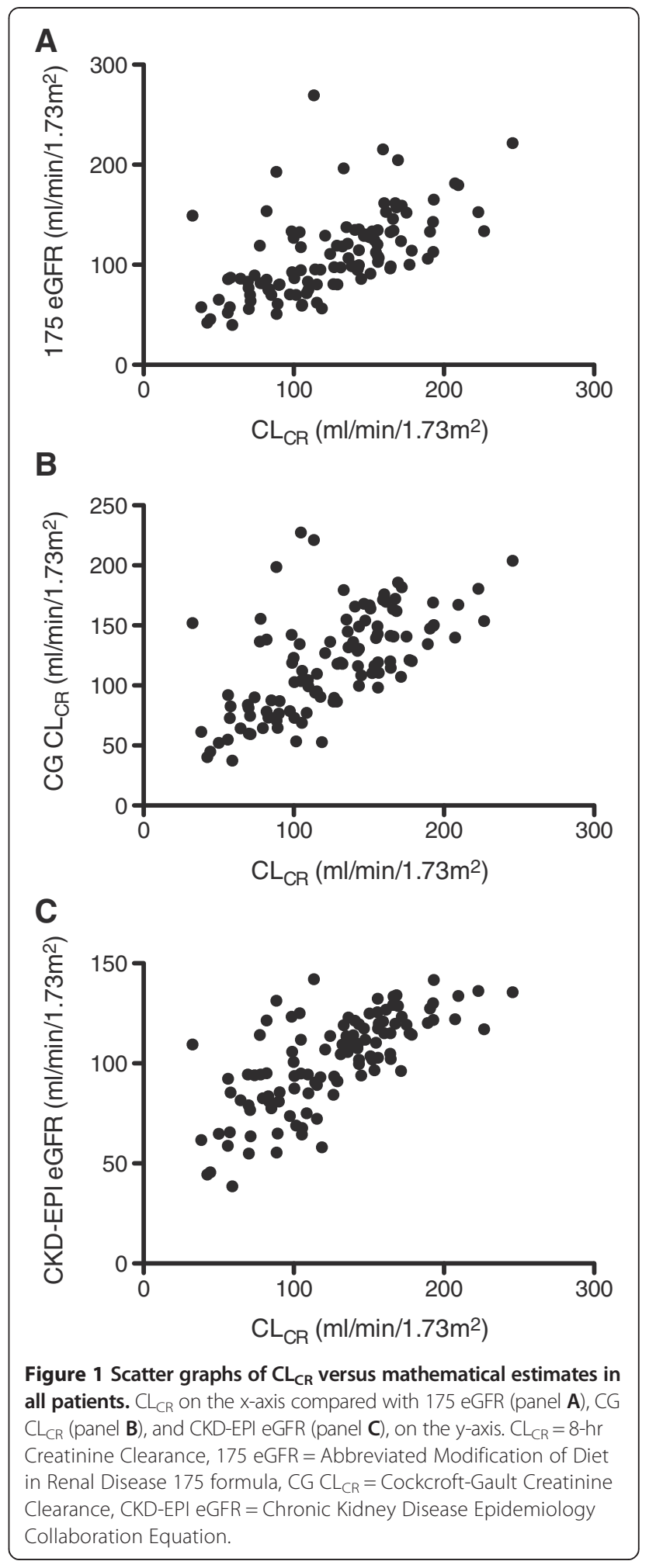

the use of eGFR formulae in the critically ill. Martin and colleagues examined the utility of MDRD eGFR and CG $\mathrm{CL}_{\mathrm{CR}}$ in comparison to 8-hr $\mathrm{CL}_{\mathrm{CR}}$ in a cohort of mainly traumatised patients [13]. $\mathrm{CL}_{\mathrm{CR}}$ measures were markedly 


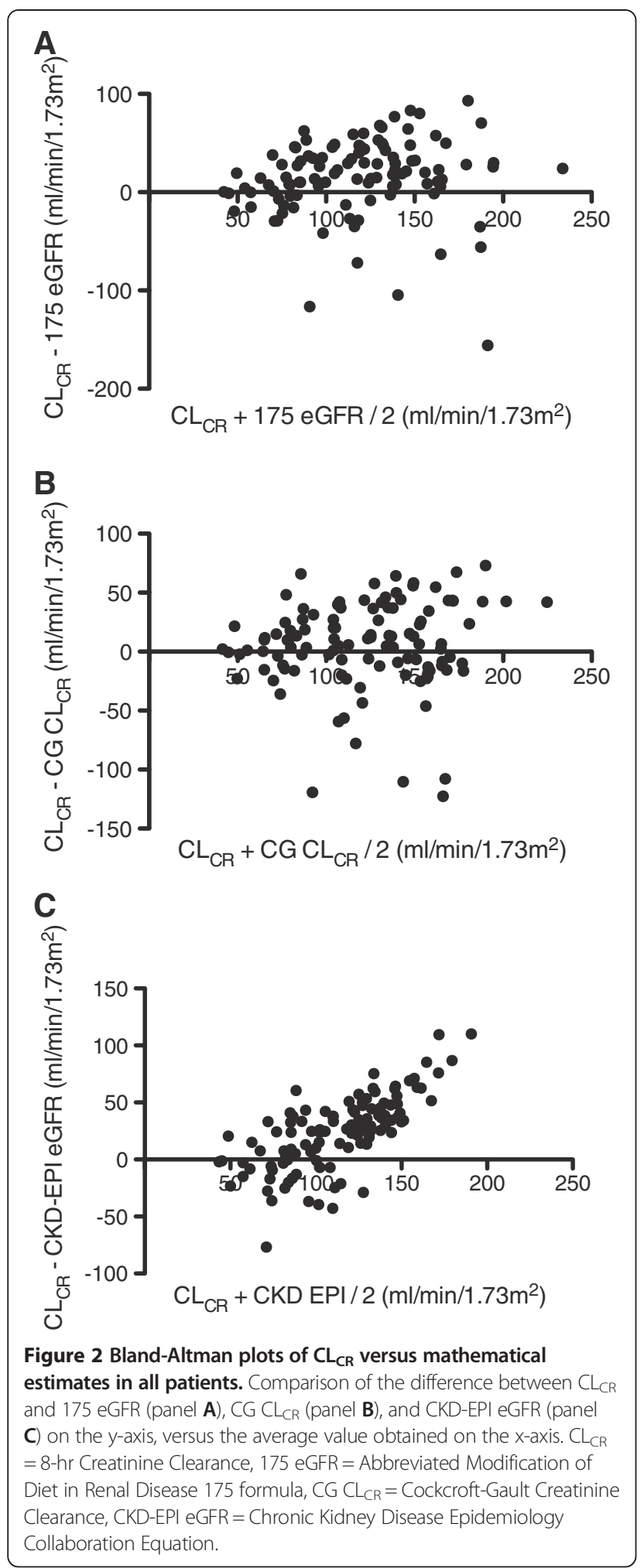

elevated, with significant bias reported with both equations. In $\sim 350$ recently admitted patients, HerreraGutierrez et al. demonstrated significant bias when comparing CG $\mathrm{CL}_{\mathrm{CR}}$ to measured values [14]. This was
Table 3 Correlation, bias and precision across different ranges of $\mathrm{CL}_{\mathrm{CR}}$

\begin{tabular}{|c|c|c|}
\hline & r ( $P$-value) & $\begin{array}{c}\text { Bias +/- precision } \\
\left(\mathrm{ml} / \mathrm{min} / 1.73 \mathrm{~m}^{2}\right)\end{array}$ \\
\hline \multicolumn{3}{|c|}{$\mathrm{CL}_{\mathrm{CR}}<90 \mathrm{ml} / \mathrm{min} / 1.73 \mathrm{~m}^{2}(\mathrm{n}=28)$} \\
\hline 175 eGFR & $0.223(0.253)$ & $-12.6+/-35.2$ \\
\hline$C G L_{C R}$ & $0.278(0.152)$ & $-15.9+/-37.2$ \\
\hline CKD-EPI eGFR & $0.351(0.067)$ & $-11.1+/-23.2$ \\
\hline \multicolumn{3}{|c|}{$\mathrm{CL}_{\mathrm{CR}} 90-119 \mathrm{ml} / \mathrm{min} / 1.73 \mathrm{~m}^{2}(\mathrm{n}=23)$} \\
\hline 175 eGFR & $0.065(0.767)$ & $10.5+/-44.4$ \\
\hline$C G C L_{C R}$ & $0.066(0.763)$ & $-0.93+/-43.9$ \\
\hline CKD-EPI eGFR & $-0.067(0.760)$ & $14.8+/-22.8$ \\
\hline \multicolumn{3}{|c|}{$\mathrm{CL}_{\mathrm{CR}} 120-149 \mathrm{ml} / \mathrm{min} / 1.73 \mathrm{~m}^{2}(\mathrm{n}=23)$} \\
\hline 175 eGFR & $0.047(0.832)$ & $22.7+/-26.1$ \\
\hline$C G C L_{C R}$ & $0.369(0.083)$ & $6.62+/-23.9$ \\
\hline CKD-EPI eGFR & $0.347(0.104)$ & $29.2+/-10.8$ \\
\hline \multicolumn{3}{|c|}{$\mathrm{CL}_{C R} \geq 150 \mathrm{ml} / \mathrm{min} / 1.73 \mathrm{~m}^{2}(\mathrm{n}=36)$} \\
\hline 175 eGFR & $0.427(0.009)$ & $36.1+/-31.3$ \\
\hline$C G C L_{C R}$ & $0.399(0.016)$ & $27.8+/-27.2$ \\
\hline CKD-EPI eGFR & $0.460(0.005)$ & $55.0+/-20.9$ \\
\hline
\end{tabular}

$\mathrm{CL}_{\mathrm{CR}}=8$-hr Creatinine Clearance, $\mathrm{CG} \mathrm{CL}_{\mathrm{CR}}=$ Cockcroft-Gault Creatinine Clearance, 175 eGFR = Abbreviated Modification of Diet in Renal Disease 175 formula, CKD-EPI eGFR = Chronic Kidney Disease Epidemiology Collaboration Equation, $r=$ Pearson correlation coefficient.

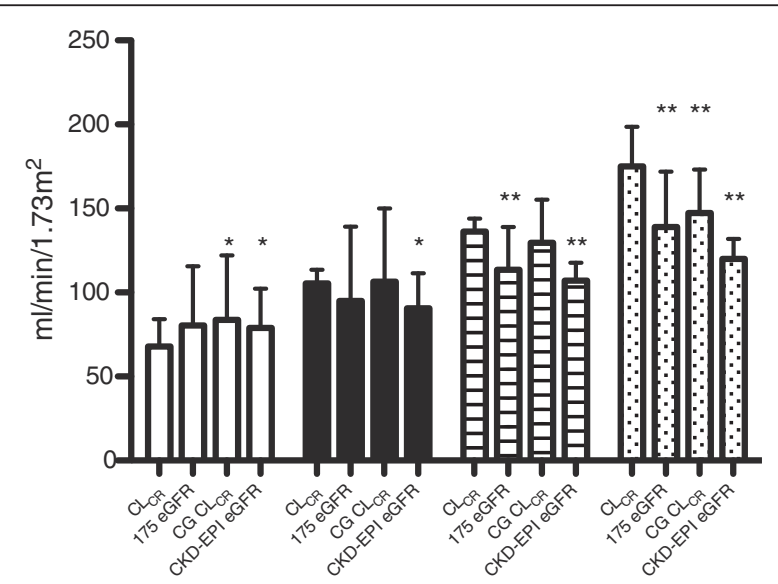

Figure 3 Comparison of $\mathrm{CL}_{\mathrm{CR}}$ with mathematical estimates over different ranges. $\mathrm{CL}_{C R}$ compared with 175 eGFR, CG CL $L_{C R}$, and CKD-EPI eGFR over different ranges. $\mathrm{CL}_{\mathrm{CR}}<90$ (open), 90-119 (solid), 120-149 (lines), and $\geq 150$ (dots) $\mathrm{ml} / \mathrm{min} / 1.73 \mathrm{~m}^{2}$. $* P<0.05$, * $P<$ 0.001. $\mathrm{CL}_{\mathrm{CR}}=8$-hr Creatinine Clearance, 175 eGFR = Abbreviated Modification of Diet in Renal Disease 175 formula, $C G \mathrm{CL}_{C R}=$ Cockcroft-Gault Creatinine Clearance, CKD-EPI eGFR = Chronic Kidney Disease Epidemiology Collaboration Equation. 
particularly evident in patients with elevated $\mathrm{CL}_{\mathrm{CR}}(\geq$ $100 \mathrm{ml} / \mathrm{min} / 1.73 \mathrm{~m}^{2}$ ), where CG estimates were markedly lower. Other studies in surgical intensive care [15], and burns injury [16], have reported similar observations.

Hoste and colleagues examined the relationship between 1-hr $\mathrm{CL}_{\mathrm{CR}}, \mathrm{CG} \mathrm{CL}_{\mathrm{CR}}$, and MDRD eGFR in twenty-eight adult patients recently admitted to the ICU [2]. Here, 25\% had a $1-\mathrm{hr} \mathrm{CL}_{\mathrm{CR}}<60 \mathrm{ml} / \mathrm{min} / 1.73 \mathrm{~m}^{2}$, despite a normal plasma CR concentration. Even with a lower range of $\mathrm{CL}_{\mathrm{CR}}$ measures, neither equation was considered specific enough for clinical use [2]. In our study, fewer patients manifest this level of renal impairment $(n=10,9.1 \%)$, limiting any definitive conclusions. However, these patients often $(n=6,60 \%)$ had a normal or near-normal calculated CKD-EPI eGFR $\left(60-119 \mathrm{ml} / \mathrm{min} / 1.73 \mathrm{~m}^{2}\right)$.

Baptista and colleagues were the first to explore the role of eGFR in the setting of $A R C$, comparing $C G \mathrm{CL}_{\mathrm{CR}}$ and MDRD eGFR with measured $\mathrm{CL}_{\mathrm{CR}}$ in eighty-six critically ill patients [17]. Calculated values were significantly less than measured $\mathrm{CL}_{\mathrm{CR}}$, with considerable bias and imprecision. In a retrospective analysis of 390 patients with ARC admitted to a single center, Grootaert and colleagues similarly reported poor agreement between $\mathrm{CG} \mathrm{CL}_{\mathrm{CR}}$, MDRD eGFR and 24-hr measured $\mathrm{CL}_{\mathrm{CR}}$ [18].

Confounding these analyses however, is often the lack of an exogenous marker of GFR. Despite this, markedly elevated renal drug elimination has been noted in many subgroups of critically ill patients [19], in parallel with higher $\mathrm{CL}_{\mathrm{CR}}$ [20]. Furthermore, recent research suggests elevated $\mathrm{CL}_{\mathrm{CR}}$ measures $\left(>130 \mathrm{ml} / \mathrm{min} / 1.73 \mathrm{~m}^{2}\right.$ ) are associated with sub-therapeutic drug concentrations [11,12] and worse clinical outcomes [21], in critically ill patients receiving antimicrobial therapy. While the implications of this phenomenon require substantial validation, the observation that $\sim 40 \%$ of patients with a normal or nearnormal CKD-EPI eGFR $\left(60-119 \mathrm{ml} / \mathrm{min} / 1.73 \mathrm{~m}^{2}\right)$ actually manifest ARC, suggests such thresholds are not simply transferrable to different estimates of renal function.

This realization is consistent with these formulae being developed outside of an ICU environment; generating results that fail to consider the unique characteristics of critical illness [22,23]. Of note, bias appeared to be greatest in emergent surgical and trauma admissions (Table 1), sub-groups where ARC has been previously well documented [24,25]. Recent data from Shimamoto et al. suggests systemic inflammation is a key factor, with increasing SIRS criteria associated with elevated renal vancomycin clearance [26]. This has important ramifications for clinical practice, where use of variable estimates of renal function may result in disparate conclusions [27,28], potentially leading to inadequate drug dosing [29].

We wish to acknowledge the following limitations. This paper reports the findings from a single-center only, and therefore may not be representative of case- mix at other institutions. Despite this, the majority of study participants manifested a systemic inflammatory response; over half received invasive mechanical ventilation; and 30\% required vasoactive support. Illness severity scores were moderate, and consistent with tertiary level ICU practice. Our inclusion criteria were designed to select a cohort of patients with normal plasma CR concentrations, as assessing renal function in the context of drug dosing remains challenging in this group. In addition, the CKD-EPI equation is reported to have improved accuracy compared to older eGFR estimates [30], particularly in patients with normal or nearnormal renal function [31].

We have employed 8-hr urinary collections, as recommended by prior research [15]. This method is not a gold standard measure of GFR, such that tubular CR secretion, and errors in measurement may have confounded our results. Without employing an exogenous filtration maker (such as inulin), it is impossible to determine which estimate is closer to the 'true' filtration rate. As such, use of endogenous $\mathrm{CL}_{\mathrm{CR}}$ may have resulted in systematically higher values. Despite this, $\mathrm{CL}_{\mathrm{CR}}$ remains a common modifier of drug dosing in clinical practice, with recent data suggesting important pharmacokinetic [11,12], and clinical [21] implications. Unfortunately no readily accessible, pragmatic, error free measure of GFR is currently available. This analysis principally serves to remind the clinician of the inherent discrepancy between estimates of GFR in the ICU.

\section{Conclusion}

In conclusion, this study has examined CKD-EPI eGFR in comparison to 8 -hr measured $\mathrm{CL}_{\mathrm{CR}}$ in a cohort of recently admitted critically ill patients with normal plasma CR concentrations. Our results suggest poor agreement between these techniques in this population. Whether this represents a true limitation of CKD-EPI eGFR, or an intuitive discrepancy based on the problems with endogenous $\mathrm{CL}_{\mathrm{CR}}$, remains uncertain. Notwithstanding this, until additional data are available on the utility of CKD-EPI eGFR for drug dose adjustment, particularly in identifying $\mathrm{ARC}$, we would recommend clinicians consider using $\mathrm{CL}_{\mathrm{CR}}$ for this purpose.

\section{Abbreviations}

AKI: Acute kidney injury; APACHE: Acute physiology and chronic health evaluation; ARC: Augmented renal clearance; CG CL $L_{C R}$ : Cockcroft-Gault creatinine clearance; CKD: Chronic kidney disease; CKD-EPI: Chronic Kidney disease epidemiology collaboration; $\mathrm{CL}_{\mathrm{CR}_{\mathrm{B}}}$ : Creatinine clearance; eGFR: Estimated glomerular filtration rate; ICU: Intensive care unit; IDC: Indwelling urinary catheter; IDMS: Isotope dilution mass spectrometry; IQR: Inter-quartile range; LOS: Length of stay; MDRD: Modification of diet in renal disease; RIFLE: Risk, injury, failure, loss, end-stage; RRT: Renal replacement therapy; SD: Standard deviation; SOFA: Sequential organ failure assessment. 


\section{Competing interests}

All of the authors declare that they have no competing interests in relation to this manuscript.

\section{Authors' contributions}

$\mathrm{AU}$ conceived the study, participated in design and coordination, performed the statistical analysis, and drafted the manuscript. FM and SNP assisted in data collection and database entry. PJ, MLS, JS, RD, and TS participated in data collection. RB and JL provided study oversight, and substantially edited the manuscript. All authors read and approved the final manuscript.

\section{Acknowledgements}

Dr. Andrew A Udy was supported in part by a Research Scholarship from the Royal Brisbane and Womens Hospital Research Foundation. The funding body had no role in data collection, analysis or the decision to submit for publication.

Received: 16 July 2013 Accepted: 30 October 2013 Published: 13 November 2013

\section{References}

1. Udy AA, Roberts JA, Shorr AF, Boots RJ, Lipman J: Augmented renal clearance in septic and traumatized patients with normal plasma creatinine concentrations: identifying at-risk patients. Crit Care 2013, 17(1):R35

2. Hoste EA, Damen J, Vanholder RC, Lameire NH, Delanghe JR, Van den Hauwe K, Colardyn FA: Assessment of renal function in recently admitted critically ill patients with normal serum creatinine. Nephrol Dial Transplant 2005, 20(4):747-753.

3. Levey AS, Bosch JP, Lewis JB, Greene T, Rogers N, Roth D: A more accurate method to estimate glomerular filtration rate from serum creatinine: a new prediction equation. Modification of diet in renal disease study group. Ann Intern Med 1999, 130(6):461-470

4. Levey AS, Stevens LA, Schmid CH, Zhang YL, Castro AF 3rd, Feldman HI, Kusek JW, Eggers P, Van Lente F, Greene T, et al: A new equation to estimate glomerular filtration rate. Ann Intern Med 2009, 150(9):604-612.

5. Matsushita K, Mahmoodi BK, Woodward M, Emberson JR, Jafar TH, Jee SH, Polkinghorne KR, Shankar A, Smith DH, Tonelli M, et al: Comparison of risk prediction using the CKD-EPI equation and the MDRD study equation for estimated glomerular filtration rate. JAMA 2012, 307(18):1941-1951.

6. White SL, Polkinghorne KR, Atkins RC, Chadban SJ: Comparison of the prevalence and mortality risk of CKD in Australia using the CKD Epidemiology Collaboration (CKD-EPI) and Modification of Diet in Renal Disease (MDRD) Study GFR estimating equations: the AusDiab (Australian Diabetes, Obesity and Lifestyle) Study. Am J Kidney Dis 2010, 55(4):660-670.

7. Johnson DW, Jones GR, Mathew TH, Ludlow MJ, Doogue MP, Jose MD, Langham RG, Lawton PD, McTaggart SJ, Peake MJ, et al: Chronic kidney disease and automatic reporting of estimated glomerular filtration rate: new developments and revised recommendations. Med J Aust 2012, 197(4):224-225.

8. Mathew TH, Johnson DW, Jones GR, Australasian Creatinine Consensus Working Group: Chronic kidney disease and automatic reporting of estimated glomerular filtration rate: revised recommendations. Med J Aust 2007, 187(8):459-463.

9. Martin JH, Fay MF, Ungerer JP: eGFR-use beyond the evidence. Med J Aust 2009, 190(4):197-199.

10. Bellomo R, Ronco C, Kellum JA, Mehta RL, Palevsky P, Acute Dialysis Quality Initiative Workgroup: Acute renal failure-definition, outcome measures, animal models, fluid therapy and information technology needs: the Second International Consensus Conference of the Acute Dialysis Quality Initiative (ADQI) Group. Crit Care 2004, 8(4):R204-R212.

11. Baptista JP, Sousa E, Martins PJ, Pimentel JM: Augmented renal clearance in septic patients and implications for vancomycin optimisation. Int $J$ Antimicrob Agents 2012, 39(5):420-423.

12. Udy AA, Varghese JM, Altukroni M, Briscoe S, McWhinney BC, Ungerer JP, Lipman J, Roberts JA: Subtherapeutic initial beta-lactam concentrations in select critically ill patients: association between augmented renal clearance and low trough drug concentrations. Chest 2012, 142(1):30-39.

13. Martin JH, Fay MF, Udy A, Roberts J, Kirkpatrick C, Ungerer J, Lipman J: Pitfalls of using estimations of glomerular filtration rate in an intensive care population. Intern Med J 2011, 41(7):537-543.

14. Herrera-Gutierrez ME, Seller-Perez G, Banderas-Bravo E, Munoz-Bono J, Lebron-Gallardo M, Fernandez-Ortega JF: Replacement of 24-h creatinine clearance by $2-\mathrm{h}$ creatinine clearance in intensive care unit patients: a single-center study. Intensive Care Med 2007, 33(11):1900-1906.

15. Cherry RA, Eachempati SR, Hydo L, Barie PS: Accuracy of short-duration creatinine clearance determinations in predicting 24-hour creatinine clearance in critically ill and injured patients. J Trauma 2002, 53(2):267-271.

16. Conil JM, Georges B, Fourcade O, Seguin T, Lavit M, Samii K, Houin G, Tack I, Saivin S: Assessment of renal function in clinical practice at the bedside of burn patients. Br J Clin Pharmacol 2007, 63(5):583-594.

17. Baptista JP, Udy AA, Sousa E, Pimentel J, Wang L, Roberts JA, Lipman J: A comparison of estimates of glomerular filtration in critically ill patients with augmented renal clearance. Crit Care 2011, 15(3):R139.

18. Grootaert V, Willems L, Debaveye Y, Meyfroidt G, Spriet I: Augmented renal clearance in the critically ill: how to assess kidney function. Ann Pharmacother 2012, 46(7-8):952-959.

19. Udy AA, Roberts JA, Lipman J: Clinical implications of antibiotic pharmacokinetic principles in the critically ill. Intensive Care Med 2013. DOI: 10.1007/s00134-013-3088-4.

20. Lipman J, Wallis SC, Boots RJ: Cefepime versus cefpirome: the importance of creatinine clearance. Anesth Analg 2003, 97(4):1149-1154.

21. Claus BO, Hoste EA, Colpaert K, Robays H, Decruyenaere J, De Waele JJ: Augmented renal clearance is a common finding with worse clinical outcome in critically ill patients receiving antimicrobial therapy. J Crit Care 2013, 28(5):695-700.

22. Hosein S, Udy AA, Lipman J: Physiological changes in the critically ill patient with sepsis. Curr Pharm Biotechnol 2011, 12(12):1991-1995.

23. Udy AA, Putt MT, Shanmugathasan S, Roberts JA, Lipman J: Augmented renal clearance in the Intensive Care Unit: an illustrative case series. Int J Antimicrob Agents 2010, 35(6):606-608.

24. Brown R, Babcock R, Talbert J, Gruenberg J, Czurak C, Campbell M: Renal function in critically ill postoperative patients: sequential assessment of creatinine osmolar and free water clearance. Crit Care Med 1980, 8(2):68-72.

25. Minville V, Asehnoune K, Ruiz S, Breden A, Georges B, Seguin T, Tack I, Jaafar A, Saivin S, Fourcade O, et al: Increased creatinine clearance in polytrauma patients with normal serum creatinine: a retrospective observational study. Crit Care 2011, 15(1):R49.

26. Shimamoto Y, Fukuda T, Tanaka K, Komori K, Sadamitsu D: Systemic inflammatory response syndrome criteria and vancomycin dose requirement in patients with sepsis. Intensive Care Med 2013, 39(7):1247-1252.

27. Wargo KA, English TM: Evaluation of the chronic kidney disease epidemiology collaboration equation for dosing antimicrobials. Ann Pharmacother 2010, 44(3):439-446.

28. Udy A, Roberts JA, Boots RJ, Lipman J: You only find what you look for: the importance of high creatinine clearance in the critically ill. Anaesth Intensive Care 2009, 37(1):11-13.

29. Chung J, Oh JM, Cho EM, Jang HJ, Hong SB, Lim CM, Koh YS: Optimal dose of vancomycin for treating methicillin-resistant Staphylococcus aureus pneumonia in critically ill patients. Anaesth Intensive Care 2011, 39(6):1030-1037.

30. Levey AS, Stevens LA: Estimating GFR using the CKD Epidemiology Collaboration (CKD-EPI) creatinine equation: more accurate GFR estimates, lower CKD prevalence estimates, and better risk predictions. Am J Kidney Dis 2010, 55(4):622-627.

31. Stevens $L A$, Schmid $C H$, Greene T, Zhang YL, Beck GJ, Froissart M, Hamm LL, Lewis JB, Mauer M, Navis GJ, et al: Comparative performance of the CKD Epidemiology Collaboration (CKD-EPI) and the Modification of Diet in Renal Disease (MDRD) Study equations for estimating GFR levels above 60 mL/min/1.73 m2. Am J Kidney Dis 2010, 56(3):486-495.

doi:10.1186/1471-2369-14-250

Cite this article as: Udy et al:: A comparison of CKD-EPI estimated glomerular filtration rate and measured creatinine clearance in recently admitted critically ill patients with normal plasma creatinine concentrations. BMC Nephrology 2013 14:250. 